\title{
Tackling ageing continence through theory, tools and technology (TACT3)
}

Jo-Anne Bichard, Eleanor van den Heuvel, Felicity Jowitt, Mary Gilhooly, Stuart G. Parker, Adele Long, Norman M. Ratcliffe, Kevin J. McKee and Patrick Gaydecki

\section{Background}

Continence problems are extremely common in the adult population and although not a direct consequence of ageing, the prevalence of incontinence does increase with age. Studies have shown that the urinary system function can decline with age (Holm et al, 1995; Malone-Lee \& Detrusor, 1993; Pfisterer et al, 2006), and can be exacerbated by concomitant diseases such as congestive heart failure, Parkinson's and diabetes. Reduced mobility is also an important factor because limitations in mobility, coupled with the weakening of bladder muscles, may cause difficulties with continence management simply because the person needs to find toilet facilities quickly and/or may have difficulty transferring onto the toilet when they get there.

For many ageing people, only the onset of dementia is feared more than incontinence. Urinary incontinence is estimated to effect between 30-60\% of women over the age of 40 (Minassian et al, 2008), and around half as many men are affected (Buckley et al, 2010). The issues surrounding continence management, including access to health services, assistive technologies and appropriate toileting facilities when away from home, are likely to increase as lifespans increase. Increased survival rates for bladder and bowel cancers will also result in the need for greater awareness of the complexity of continence management, including appropriate bins in both male and female toilet provision for the disposal of continence pads, colostomy and urostomy bags.

The complexity of issues surrounding continence management, have been investigated by a UK multi-disciplinary research team working under the project title Tackling Ageing Continence through Theory Tools and Technology (TACT3). The team comprising engineers, chemists, health researchers, designers and social anthropologists is funded by the New Dynamics of Ageing Programme, 'a seven year multidisciplinary research initiative with the ultimate aim of improving quality of life of older people. The programme is a unique collaboration between five UK Research Councils ${ }^{1}$, and is the largest and most ambitious research programme on ageing ever mounted in the UK' (www.newdynamics.group.shef.ac. uk).

The TACT3 project comprises four work packages that are individually managed by members of the research team. One work package focuses solely on knowledge transfer of the research outputs and the management of the overall project. Another work package, entitled 'Challenging Environmental Barriers' has focused on the barriers in the built environment that prevent older people with continence concerns from participating in wider social life, namely access to publicly available toilet facilities. We also have a work package entitled 'Improving Continence Interventions and Services' which is exploring patient, carer and service providers' experiences in receiving and delivering National Health Service (NHS) continence management treatments. The fourth workpackage 'Developing Assistive Technologies' has worked with users to develop devices that promote confidence, improve health and therefore may facilitate greater social interaction for older people with continence management concerns.

\footnotetext{
${ }^{1}$ Economic \& Social Research Council (ESRC); Environmental \& Physical Sciences Research Council (EPSRC); Biotechnology and Biological Sciences Research Council (BBSRC); Medical Research Council (MRC); Arts and Humanities Research Council (AHRC).
} 


\section{Developing Assistive Technologies}

Continence management difficulties have a huge impact both economically and in terms of quality of life for older people (Temml et al, 2000). The loss of continence is identified as being one of the main reasons for a person's move into residential care, due to family carers feeling they are unable to cope with the consequences of the condition (Thom et al, 1997). In addition, continence difficulties impact people beyond the physical effort and expense of management (purchase of pads and repeated clothes washing), as the problem is strongly associated with reduced self-esteem, social isolation and depression (Shaw, 2001).

For social and hygienic problems caused by unwanted urine loss, continence pads are often chosen as the main option for continence management. Estimates of the global market for continence pads, in 2008, reached $\$ 4.4$ billion (Euromonitor, 2010). The large continence pad market has become a core indicator for the TACT3 research suggesting that large numbers of adults who require continence pads could benefit from appropriate technologies that may improve the users' experience. Previous studies have identified that one of the most important fears to arise from 'treatment effects' of using continence pads, concern leakage and odour (Getliffe et al, 2007). When incidents of pad leakage occur, urine often spreads to underwear and outer clothing, and can further leak onto seating surfaces. Pad leakage often results in increased work to change and launder clothing and clean furnishings. Yet, a far worse consequence for many pad users is the embarrassment associated with a major pad leak. Getliffe et al (2007) found that the embarrassment of leakage created more anxiety then the physical consequences of the leakage event. In addition, the study found that odour concerns were high for pad wearers, regardless of the severity of the continence problem (Ibid, 2007).

These concerns, were voiced by Cheryle Gartley founder and president of Simon Foundation for Continence USA ${ }^{2}$. She felt that there was a strong case for the development of 'early warning' technologies that could inform pad wearers of a pad leakage event affording them the opportunity to take appropriate steps to prevent 'an accident', and to manage odour concerns. In response to this request, The TACT3 team, based at Brunel University, the University of Manchester, the University of the West of England and the Bristol Urological Institute developed the following products:

1) Smart underwear with integral sensors and a detachable signalling system that can detect a leak from the continence pad and alert the wearer. The alerting signal warns the wearer, allowing them to deal with the problem before the urine spreads to outer clothes or furniture. The device should save the work and the cost of washing and cleaning. More importantly it should increase the confidence of the wearer who will know immediately if the pad fails and not have to deal with the embarrassment of a wet patch on clothes or furniture.

2) A colour change odour detector that is able to detect sub-olfactory levels of ammonia. As previously noted, worry about odour is a major concern for continence pad users, regardless of the severity of the continence problem. Therefore an objective measure of odour would be invaluable for increasing confidence and self esteem for pad users (as well as carers who may share concerns regarding odour). The colour change odour detector that is being developed reassures pad users by alerting them to the odour of stale urine, before the human nose can detect it. 
User focused design techniques were employed to design the ergonomic and aesthetic features of the Smart underwear and odour detector. Focus groups of 2-5 women were invited to discuss the problems of pad leakage and odour, underwear styles, odour detector configurations, alerting methods and the appearance of the devices.

\section{Smart Underwear (Brunel University \& University of Manchester)}

The Smart Underwear is a conventional looking garment with twin tracks of conductive yarn sewn into an insert in the underwear. The course of these pathways follows the anticipated edge of a disposable continence pad in use. The conductive yarn pathways terminate with a press-stud at one end of each track, to which the signalling unit is attached. These 'sensors' activate the signalling unit in the presence of urine. When thus activated, a microcontroller begins a sequence to energize the vibration unit. This vibration alerts the wearer of the underwear to the overflow of urine. The means of alerting, style of underwear, position of the signalling unit and colour of the underwear were selected by the focus groups.

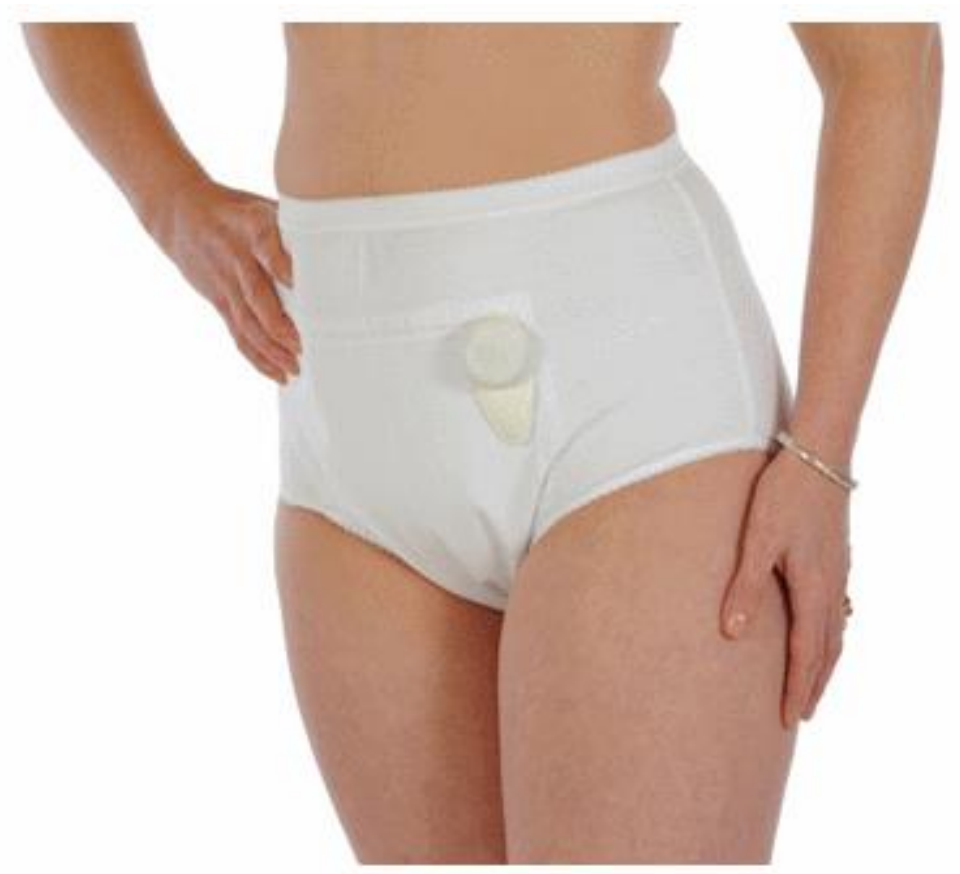

Figure 1: Smart Underwear with Signalling Unit

\section{Smart Underwear Evaluation (Bristol Urological Institute)}

The Smart underwear has been clinically evaluated in a pilot study, which aimed to identify any modifications that should be made to optimize the device before the full evaluation was carried out. Participants reported that they were alerted by the Smart Underwear in $94 \%$ of pad leakage events and in $74 \%$ of those events they were not aware that the pad had leaked until the device alerted them. Urine leakage from the pad was restricted to the underwear in $97 \%$ of leakage events, reaching the outer clothing on three occasions and spreading to furnishing just once.

In the evaluation questionnaire at the end of the study, five out of six women 'definitely felt more confident' when wearing the Smart Underwear. Comments about the Smart Underwear included "found product very useful", "felt much more confident about going out without worrying that I was going to wet myself", and "comfortable, discreet, 
less washing of clothing due to alerts". The pilot study results were extremely promising and although two women experienced significant problems with false alerts attributed to menopausal sweating, data from the focus group design work indicates that women prefer the device to be over sensitive rather than not sensitive enough. The Smart Underwear device has been developed to meet an important need for people who use continence pads. User focused design techniques have been successfully applied to produce a first clinical prototype that has been found acceptable and useful by the participants in the pilot study. The full clinical evaluation is currently in progress.

\section{Odour Detector (Brunel University \& University of the West of England)}

The odour detector uses a dye that changes colour from yellow to blue in the presence of sub-olfactory levels of ammonia. Ammonia is produced by the breakdown of urea, which is always present in urine. Although urine odour is a complex mixture of volatiles, ammonia is used as a reference component for detection. The colour change element in the dye turns blue when the product detects the presence of very low levels of ammonia. The dye film is encapsulated in a discreet product, for example a key ring or bracelet so that the user can hold it in their lap whenever they are concerned about odour. Most people who use continence pads do not smell of stale urine, but they are afraid that they might. The primary purpose of the odour detector device therefore is reassurance. Lockets could be made with a colour change element, that could be incorporated in either bracelets or key ring fobs. The colour changing jewellery could be fabricated at an affordable cost.

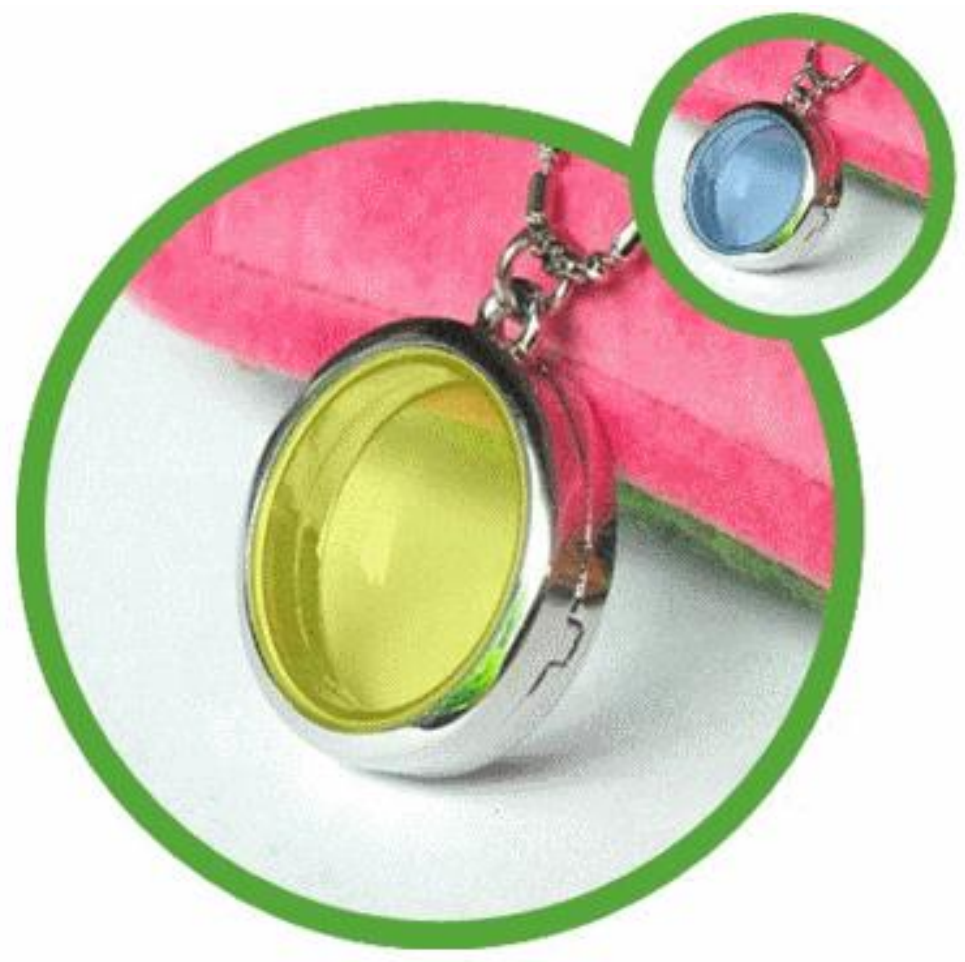

Figure 2: Colour Change Odour Detector

\section{Improving Continence Interventions and Services}

Jointly co-ordinated by the University of Sheffield, Dalarna Research Institute and Dalarna University, this work package consists of two parallel studies, in which the views and experiences of continence service users and service providers are explored in 
order to identify key characteristics that may result in effective treatment outcomes and improved quality of service.

The first study is focused on improving continence interventions and services for older people by enhancing dignity and control in late life transitions: and focuses on the impact of matching care to need on health outcomes in people with urinary incontinence.

\section{Improving Continence Interventions and Services - The Users Perspective}

The study is comparing the provision of care for older people and their carers who experience different continence care 'pathways', routes that access care. The project is establishing the key features of continence service provision that best meet the selfperceived needs of older people. Capturing the experiences and attitudes of patients reporting continence management concerns and from different care settings (such as domestic and sheltered care), will provide a valuable insight, from the perspective of the service user, concerning the level and quality of care and treatment provided by NHS Continence services to older people who are managing continence difficulties.

There are three key objectives to the first study, they are:

1. To compare continence-specific quality of life outcomes for older people with urinary continence management concerns who experience different continence care journeys of treatment (care pathways).

2. To investigate how older people with continence concerns perceive the cause of their condition, and their attitudes and perceived barriers to seeking help and treatment.

3. To investigate how older people with continence concerns perceive their health and social care service needs and the preferred characteristics of those services.

The fractured nature of service provision in UK health services often results in widely differentiated care being offered. In evaluating care of continence conditions from across a number of different sites the study will assess which service incorporates a higher quality and cost effective provision. The research design of this work package is evaluating and comparing existing provision of continence care for older people in the NHS using a mixed methods approach.

To meet the research design, 150 participants are being recruited from three different settings in South Yorkshire. The settings are a specialist clinic for older people (Barnsley District General Hospital); a community clinic (Sheffield Primary Care Trust) and a surgical setting (Urogynaecology, Sheffield Teaching Hospital). The inclusion criteria for research participants are; patients aged over 50 years with a diagnosis of urinary incontinence and able to give informed consent.

All participants are being asked to complete a short questionnaire about the care they have received, and a continence-specific quality of life measure. A sub-sample of participants have been asked to take part in a semi-structured face-to-face interview with a member of the research team to elicit more detailed information about their needs and preferences for continence service delivery. The interviews will also explore their reasons for seeking treatment and any barriers that they may have encountered whilst seeking treatment and explore their attitudes towards different treatment options.

The King's Health Questionnaire, a previously validated and widely used measure to assess the quality of life of people with incontinence will be used as an 'outcome measure'. A secondary outcomes measure, the Patient's Global Impression of Improvement and the Incontinence Severity Index, will also be incorporated. 
Data from the questionnaires will be analysed using ANOVA $^{3}$ to allow a comparison of care across settings. With the participant's consent all interviews have been digitally recorded and transcribed verbatim. The transcripts are being analysed using the framework approach, in which the data is coded according to a priori categories derived from the literature and the interview guide. Emergent themes will then be compared across the different groups of service users. At time of writing 100 questionnaires have been completed by participants and 43 participants have been interviewed. In addition, five carers of individuals with continence concerns have been interviewed.

The second study, running in parallel with the first, will explore possibilities for improving continence services for older people, through evaluating health care professionals' views and experiences of continence management and service characteristics.

\section{Improving Continence Services and Interventions - The Professionals Perspective}

There are two aims of this second study; firstly to examine the views and experiences of continence service managers from NHS Trusts and secondly to examine the views and experiences of health care professionals working within continence care services. By evaluating care service managers and health care professionals' experiences in continence care services and mapping these findings onto the results of the first study, collectively, this information may help towards raising standards in NHS continence service delivery and care.

The second study uses a mixed methods approach and has been designed in two phases. In Phase 1, qualitative data from telephone interviews is being collected from 20 continence service managers from NHS Trusts and analysed using Framework Analysis (Ritchie \& Spencer, 1994). The sample of service managers is 'purposive' and represents the range of continence services available around the UK including, rural and urban, primary and acute care. In addition, recruitment has covered a wide geographical area that represents rural services such as those available in Cumbria and Cornwall, to those of inner cities such as London and Birmingham, in community and hospital services.

Participants are being asked to discuss in detail, key characteristics of the urinary incontinence service they provide for older people and how their service and treatment outcomes might be improved. In the second phase of this study, a structured on-line questionnaire will collect quantitative data from 200 health care professionals. It is hoped this data will generate information about key service characteristics and continence management. Such data will provide insights into the delivery of effective and ineffective treatment outcomes for older people with urinary incontinence.

At time of writing, 13 service managers have been interviewed, and 13 health professionals have completed the online questionnaire. In order to address the shortfall in participant recruitment for the online questionnaire, we intend to recruit potential participants at the Royal College of Nursing Continence conference in November 2011. The study will be com- plete by April 2012.

\section{Challenging Environmental Barriers to Continence}

Previous research on public toilet provision found that older people with continence concerns restricted the time they are away from home, and the distances they might travel due to discomfort felt at being away from a toilet, or not knowing where the

\footnotetext{
${ }^{3}$ Analysis of VAriance between groups.
} 
nearest facilities are (Bichard \& Hanson, 2009). A report by the UK charity Help the Aged $^{4}$ found that there has been a marked decline in public toilet provision ${ }^{5}$. Swithinbank \& Abrams (1999) have noted that a lack of access to toilets when away from the home can lead to quality of life concerns, which Norton (1982) identified as including social isolation and avoidance of travelling or using social space. Such reduced mobility often means that people withdraw from wider social activity (Wyman, 1994) which often includes family and friends and going to work (Lam et al, 1992). This in turn, can lead to greater instances of low self-esteem, depression and loneliness (Atkins, 2001) and draw further on resources for health and social services.

Older women, often report continence concerns, many of whom will journey plan based on access to toilet provision (Greed, 2003). During working hours provision may be extended into the private sector with people accessing shops and services to use toilet facilities. However, at the close of business, many city centres become void of suitable toilet provision and effectively deny many older people access to city space and participation in the evening economy. Holland et al, (2005) argue that the pleasures and challenges of life beyond the home should not be denied to older people and that an age friendly environment is essential for quality of life in old age.

\section{Current Design Innovation in Toilet Provision}

Although the number of UK public toilets in use has decreased, there have been a number of innovative designs that attempt to address the issue of toilet provision for the public. The Automatic Public Convenience (APC) also known as the 'Superloo' or 'Tardis' began appearing on UK streets in the early 1990s, yet has not found favour with the public. Bichard \& Hanson (2009) found that many people would prefer to extend journeys to the top floor of department stores rather than use an APC. In addition, the researchers found that no women over the age of 65 would use this design of toilet.

\footnotetext{
${ }^{4}$ Now known as Age UK http://www.ageuk.org.uk/

${ }^{5}$ Public Toilets are those owned and operated by UK local authorities. There is no statutory requirement to provide this service but it has previously been considered a public service.
} 


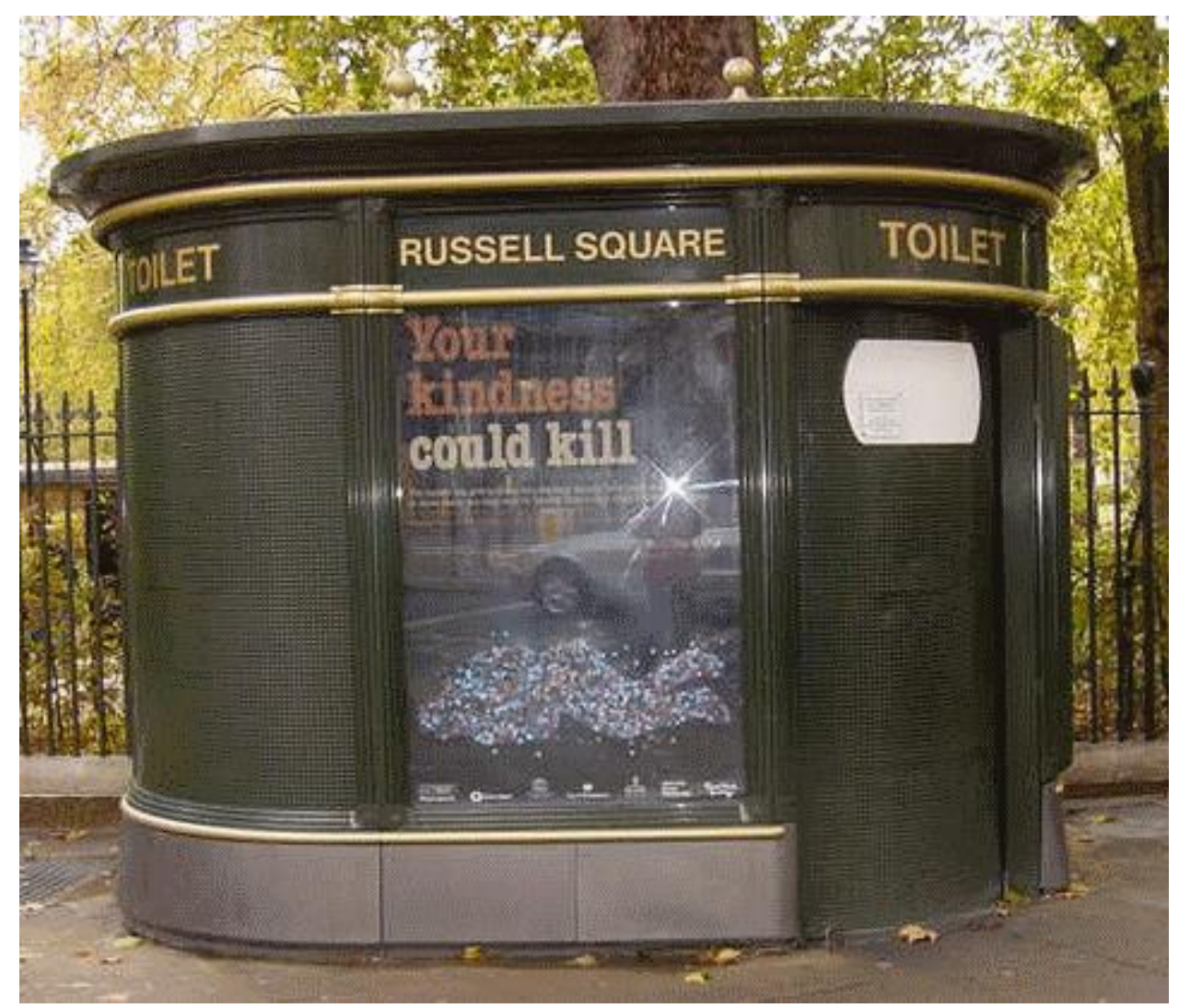

Figure 3: Automatic Public Convenience (APC)

Another recent innovation, the Uri-Lift, seeks to address the requirements of evening toilet provision. This 'pop-up' urinal is raised by remote control at dusk and set back in the ground at dawn. Designed primarily to counteract the effects of street urination, including unsightly behaviour and environmental distress due to urinary malodour, the Uri-Lift has become a popular option among public providers. However, the Uri-Lift and other temporary urinal solutions noticeably only address the needs of the male population. Even within this sector they fail to provide a toileting solution for men who have Paruresis (shy bladder syndrome), men who observe faith and hygiene practices with regards to toileting, and older men who find such urinals unacceptably exposed. 


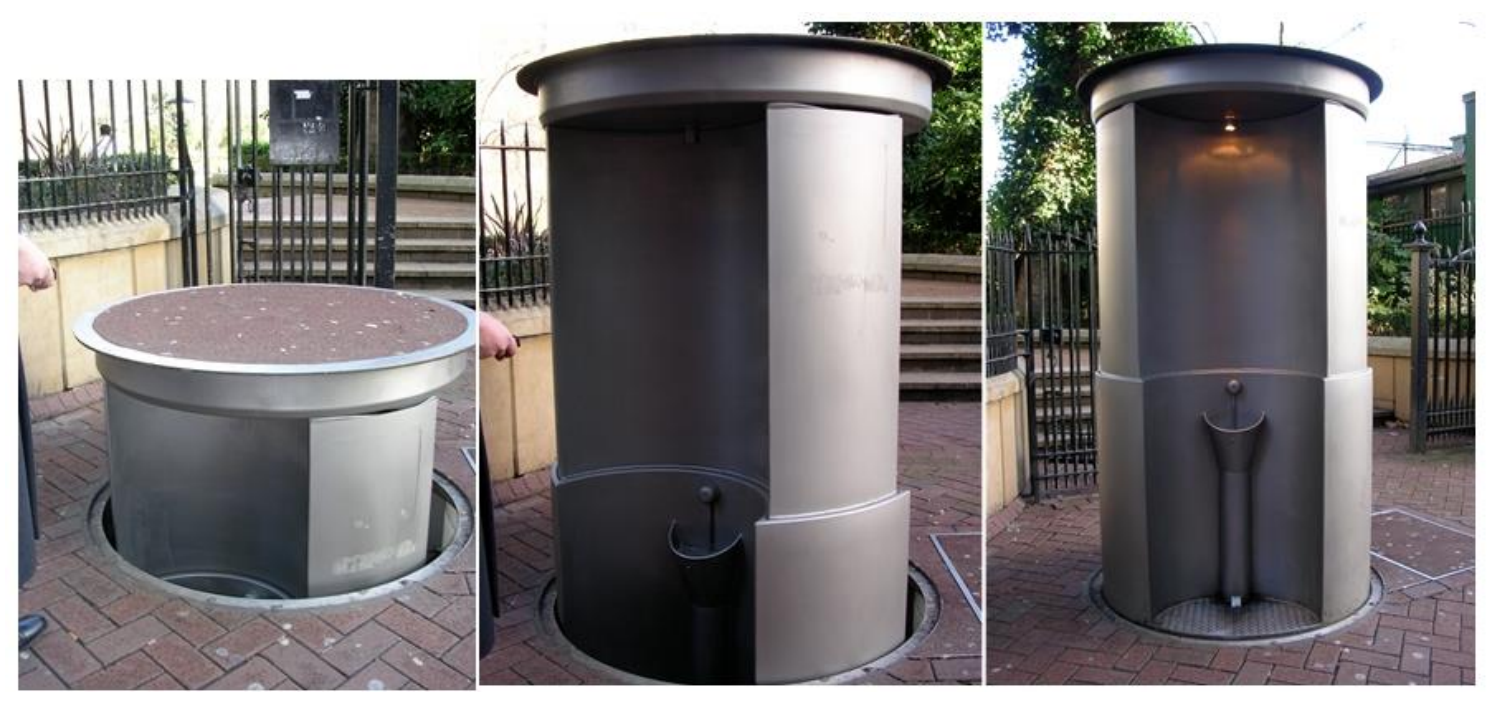

Figure 4: Urilift Urinal

These innovations in public toileting provision have not achieved preference amongst users, and have therefore not met people's needs, especially those of the ageing population. Therefore, the researchers at the Royal College of Art Helen Hamlyn Centre for Design have investigated how provision can best be maximised to offer toileting facilities that are well designed for hygiene, access, comfort and dignity, that will be welcomed by members of the public and that will also be secure, to meet the needs of the providers.

\section{User Participation - The Public}

Between 2008-2011, the 'Challenging Environmental Barriers' work package has focused on user participation to understand the issues people face when finding, accessing and using, toilet facilities when away from home. Users have been defined in this project as being both members of the public and providers of toilet facilities.

In the first year of the research the project focused on the needs of members of the public. Initially, the project was just going to focus on the needs of people aged over 50 . However, a first consultation with the New Dynamics of Ageing Older People's Reference Group ${ }^{6}$ revealed that the issue of a lack of toilets was not just an 'age based' concern but a problem that faces all ages. The research team were encouraged to include members of the public who represented a wider age range. We therefore incorporated a methodology in which we included the toileting needs of the ages $0^{7}-101$. By charting the needs of these different ages (both male and female) the research was able to build a picture of key aspects of design that participants across the age ranges liked and disliked. Semi-structured interviews with members of the public were conducted over the telephone, in person on a one-to-one basis and also in groups of 3-4 people. In total 101 people were interviewed. A note form of transcription was used in which key design elements were emphasised. Interviewees were also invited to take part in design workshops, which were held after the interviews were complete. In total 7 people ( 2 men 5 women) attended the workshops in which the researchers designed a participatory design game for the attendees to 'build their own toilet facilities'. Working in two groups

\footnotetext{
${ }^{6}$ The New Dynamics of Ageing Older People's Reference Group (OPRG), consists of members of the public some of whom have expertise in the issues of Ageing, to oversee and consult on the projects involved in the programme. The OPRG have been instrumental in guiding research even through funding application and revision stages.

${ }^{7}$ The age 0 was illustrated by the needs of a newborn baby.
} 
of two and one group of three, the participants were given pictorial references of key elements that had arisen from the interview sessions and asked to incorporate them in order of importance into their designs. The grouping of participants also added a degree of wider design consideration. One pair consisted of an older man and a younger woman, another pair of older and younger women. The group of three consisted of a woman in her middle years, whose reduced mobility required her to use a wheelchair, an older man and a younger woman.

From this workshop there emerged three key themes that users considered a priority. These were:

- Cleanliness - it was important that toilets are seen to be clean, to communicate wider hygiene confidence.

- Functionality - equipment in the facilities had to be seen to work.

- Technology - users appreciated technological innovations to improve toilet provision.

Data from the interviews and workshops were then consolidated to create four personas; Yasmin a 26 year old Trainee Teacher with Irritable Bowel Syndrome (IBS), Paul a 38 year old photographer with three young children, Judith aged 60 and recently retired, who also cared for her mother and finally Leonard aged 82 who required a walking aid for physical mobility. The personas were specifically developed to communicate a cross section of user needs to providers who were the second group of users consulted in year two of the project ${ }^{8}$.

\section{User Participation - The Providers}

UK toilet provision is currently divided between a number of varied providers. Some 'stand-alone' facilities are offered by local authorities ${ }^{9}$, other provisions may be part of the transport infrastructure (bus and train stations). There are also toilets provided in cafes, bars, pubs and restaurants. Whilst there has been a decline in UK 'public' toilet provision, there are still 'publicly accessible' toilets widely available. To understand some of the issues providers face in maintaining provision, especially to a standard expected by users, we interviewed 22 different providers and associated professionals. These included council officers overseeing public and community toilet schemes ${ }^{10}$ as well as representatives from park and transport services, cleaning contractors, architects, and business providers.

The key issues raised by many of the providers, included how to keep the toilet facilities to a high standard expected by members of the public, and deter non-toileting behaviour such as graffiti and vandalism, illegal drug use and public sex activities.

Bringing the experiences of both types of 'users' together, the researchers found that an often overlooked area within the service of toilet provision, concerned information about

\footnotetext{
${ }^{8}$ There were no personas created that represented people with disabilities as a set of 42 personas representing a range of disabilities and chronic health conditions and their experience of finding and accessing toilet facilities were created by Hanson, Bichard \& Greed (2007) see http://eprints.ucl.ac.uk/4847/

${ }^{9}$ There are currently 406 UK councils responsible for toilet provision, although there is no statutory requirement for toilet to be provided.

${ }^{10}$ Community Toilet Schemes are initiatives operated by local authorities who pay a stipend to businesses' for them to open their toilets to members of the public who are not only customers.
} 
facilities, such as where they are, and the level of access they provide (including a unisex accessible cubicle and baby change facilities). For members of the public, especially

older people and those with continence concerns, information was often not provided, or if provided often inaccurate. Poor information often had serious consequences for these users. For providers, ensuring information was current and up-to-date proved to be a costly challenge. Yet, the provision of good information on toilet provision would ensure that people knew about facilities and probably increase usage. In turn - such an increase of usage may deter non-toileting behaviours that tend to take place when facilities are not used.

\section{The Great British Public Toilet Map}

The researchers on the Challenging Environmental Barriers work package found that current UK toilet provision is not centrally collated and no national map or database of toilets exists. However, the UK Government's commitment to greater transparency in local government has developed a strategy called Open Data in which information about services is released, analysed and used by members of the public. By incorporating Open Data on public toilet provision, the researchers developed The Great British Public Toilet Map (GBPTM), a pub- lic participation website to improve information about the UK's public toilets. The GBPTM aims to encourage local authorities to provide and maintain public toilet information as Open Data, and in a cost effective way.

The GBPTM will show which councils publish Open Data about their toilets. Toilet data already released is shown on the map so that people can find the facilities. If a council has not yet published the Open Data about provision, users will be able to contact the council with a sample letter to explain why this information is useful, and encourage the council to contribute Open data to The Great British Public Toilet Map.

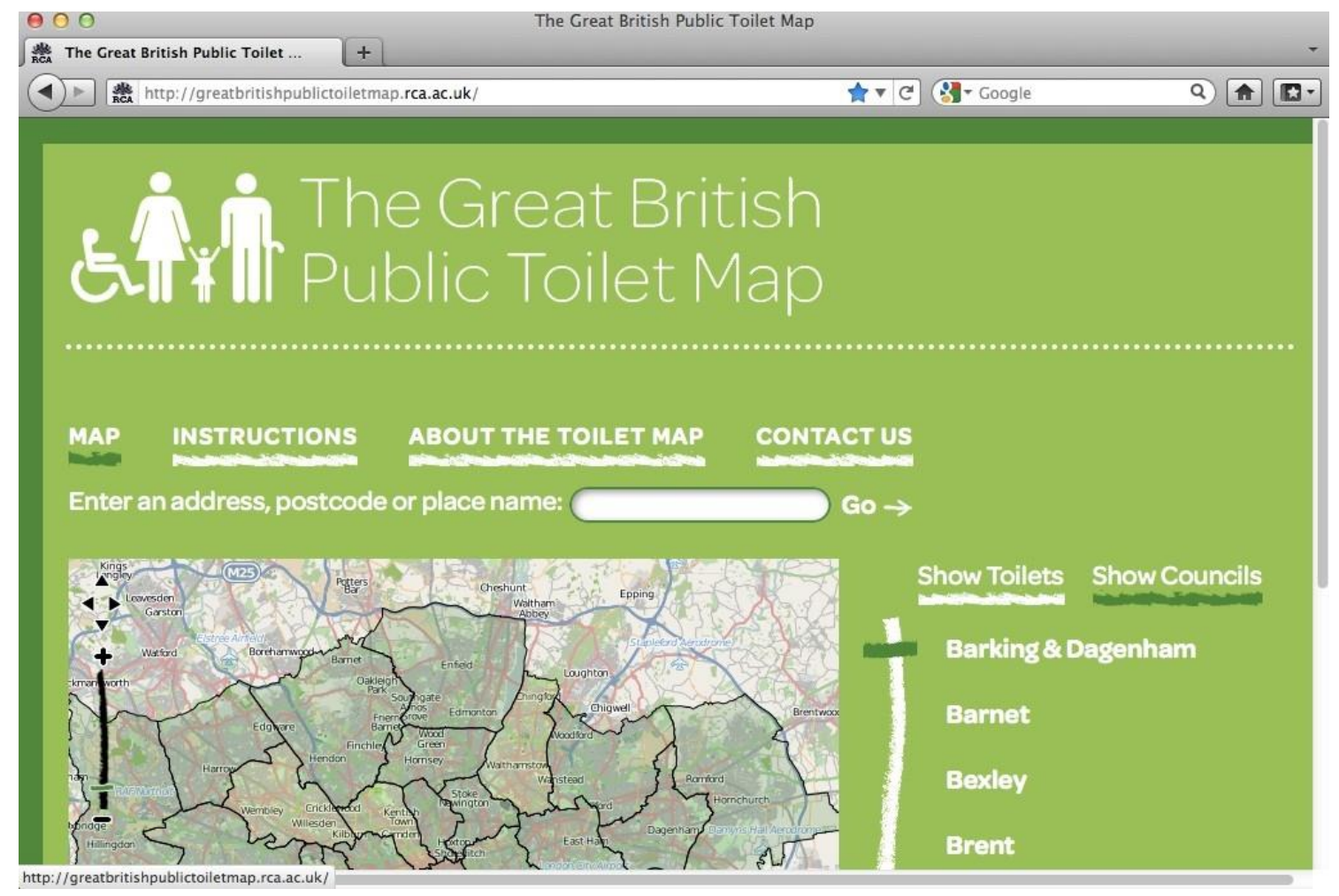

Figure 5: The Great British Public Toilet Map 


\section{Conclusion}

The Tackling Ageing Continence through Theory Tools \& Technology multidisciplinary research project has focused on investigating three key areas of concern for people with continence concerns, namely developing assistive devices, improving interventions and services, and understanding the environmental barriers, especially within the context of the UK's ageing population. In total nearly 480 people, comprising members of the public and professionals, will have contributed their expertise between the three work packages. It is hoped that the outcomes of this research: smart underwear, odour sensing devices, The Great British Public Toilet Map, and improved knowledge of NHS continence service provision will provide some measure of relief to many people who experience reduced quality of life and wellbeing due to managing their continence concerns.

Yet, concerns about managing continence are not solely a UK based phenomenon. They are a global phenomena, and therefore cost effective solutions that meet the needs of a range of users are required. 


\section{References}

Atkins, W.S. (2001) Older People their transport needs and requirements. Department of Transport, Local Government \& the Regions, London.

Bichard, J. \& Hanson, J. (2009) 'Inclusive Design of ‘Away from Home' Toilets' in Designing Sustainable Cities. Eds R. Cooper, G Evans \& C. Boyko. WileyBlackwell, UK.

Buckley, B.S. \& Lapitan, M.C. (2010) 'Prevalence of urinary incontinence in men, women, and children: current evidence': Findings of the Fourth International Consultation on Incontinence in Urology; 76: pp 265-270.

Getliffe, K., Fader, M., Cottenden, A., Jamieson, K., \& Green N. (2007) 'Absorbent Products for incontinence: 'treatment effect' and impact on quality of life' in Journal of Clinical Nursing 16: pp 1936-45.

Greed, C. (2003) Inclusive Urban Design: Public Toilets, Architectural Press, Elsevier, Oxford.

Help the Aged. (2007) Nowhere to Go; Public Toilet Provision in the UK, Help the Aged, London.

Holland, C., Kellaher, L., Peace, S., Scharf, T., Breeze, E., Gow, J., \& Gilhooly, M. (2005) 'Getting out an about' in A Walker (Ed) Understanding Quality of Life in Old Age. Open University Press, UK.

Holm, N.R., Horn, T., \& Hald, T. (1995) Detrusor in ageing and obstruction in Scandinavian Journal of Urology Nephrol; 29: pp 45-49.

Lam, G.W., Foldspang, A., Elving, L.B., \& Mommsen, S. (1992) Social Context, social abstention and problem recognition correlated to adult female urinary incontinence in Danish Medical Bulletin 39: pp 565-570.

Malone-Lee, J.G., \& Wahedna, I. (1993) Characterisation of detrusor contractile function in relation to old age in British Journal of Urology; 72: pp 873-880.

Minassian, V.A., Stewart, W.F. \& Craig Wood, G. (2008) Urinary Incontinence in Women: Variation in Prevalence Estimates and Risk Factors in Obstetrics \& Gynecology: Vol111 (2), Pt 1- pp 324-331.

Norton, C. (1982) The effects of urinary incontinence in women in International Rehabilitation Medicine 4: pp 9-14.

Pfisterer, M., Griffiths, D., Schaefer, W., and Resnick N. (2006) The Effect of Age on Lower Urinary Tract Function: A Study in Women, in Journal of the American Geriatrics Society 54 (3), pp 405-412.

Ritchie J. \& Spencer L. (1994) Qualitative data analysis for applied policy Research, in Analysing Qualitative Data (Eds) A. Bryman \& R.G. Burgess. Routledge, London.

Shaw, C. (2001) A review of the psychosocial predictors of help-seeking behaviour and impact on quality of life in people with urinary incontinence, in Journal of Clinical Nursing, 10 (1), pp 15-24.

Swithinbank, L.V. \& Abrams, P. (1999) The impact of urinary incontinence on the quality of life of women in World Journal of Urology, 17: pp 225-229.

Temml, C., Haidinger, G., Schmidbauer, J., Schatzl G., and Madersbacher, S. (2000) Urinary incontinence in both sexes: prevalence rates and impact on quality of life and sexual life in Neurourol. Urodyn: 19, pp 259-271. 
Thom, D.H., Haan, M.N. \& van den Eeden, S.K. (1997) Medically recognized urinary incontinence and risks of hospitalization, nursing home admission and mortality, in Age and Ageing; 26: 367-374. 